\title{
THE SUITABILITY OF TERRESTRIAL LASER SCANNING FOR BUILDING SURVEY AND MAPPING APPLICATIONS
}

\author{
N. A. S. Russhakim ${ }^{1}$, M. F. M. Ariff ${ }^{1}$, Z. Majid ${ }^{1}$, K. M. Idris ${ }^{1}$, N. Darwin ${ }^{1}$, M. A. Abbas ${ }^{2}$, K. Zainuddin², A. R. Yusoff ${ }^{1}$ \\ ${ }^{1}$ Geospatial Imaging and Information Research Group, Faculty of Built Environment and Surveying, Universiti Teknologi Malaysia, \\ 81310, Skudai, Johor, Malaysia-mfaridma@utm.my \\ ${ }^{2}$ Centre of Study for Surveying Science and Geomatic, Faculty of Architecture Planning and Surveying, Universiti Teknologi \\ MARA, Malaysia
}

\section{Commission II}

KEY WORDS: Terrestrial Laser Scanning, Handheld Mobile Laser Scanning, Building Survey \& Mapping

\begin{abstract}
:
The popularity of Terrestrial Laser Scanner (TLS) has been introduced into a field of surveying and has increased dramatically especially in producing the 3D model of the building. The used of terrestrial laser scanning (TLS) is becoming rapidly popular because of its ability in several applications, especially the ability to observe complex documentation of complex building and observe millions of point cloud in three-dimensional in a short period. Users of building plan usually find it difficult to translate the traditional twodimensional (2D) data on maps they see on a flat piece of paper to three-dimensional (3D). The TLS is able to record thousands of point clouds which contains very rich of geometry details and made the processing usually takes longer time. In addition, the demand of building survey work has made the surveyors need to obtain the data with full of accuracy and time saves. Therefore, the aim of this study is to study the limitation uses of TLS and its suitability for building survey and mapping. In this study, the efficiency of TLS Leica C10 for building survey was determined in term of its accuracy and comparing with Zeb-Revo Handheld Mobile Laser Scanning (MLS) and the distometer. The accuracy for scanned data from both, TLS and MLS were compared with the Distometer by using root mean square error (RMSE) formula. Then, the 3D model of the building for both data, TLS and MLS were produced to analyze the visualization for different type of scanners. The software used; Autodesk Recap, Autodesk Revit, Leica Cyclone Software, Autocad Software and Geo Slam Software. The RMSE for TLS technique is $0.001 \mathrm{~m}$ meanwhile, RMSE for MLS technique is $0.007 \mathrm{~m}$. The difference between these two techniques is $0.006 \mathrm{~m}$. The 3D model of building for both models did not have too much different but the scanned data from TLS is much easier to process and generate the 3D model compared to scanned data from MLS. It is because the scanned data from TLS comes with an image, while none from MLS scanned data. There are limitations of TLS for building survey such as water and glass window but this study proved that acquiring data by TLS is better than using MLS.
\end{abstract}

\section{INTRODUCTION}

\subsection{Terrestrial Laser Scanner}

Terrestrial Laser Scanner (TLS) is one of instrument that can provide efficiency in surveying. According to Arayici, 2007, TLS can also provide data at unreachable place. Even though the shape of the building is complex yet the TLS able to produce detail of the 3D point cloud. Instead of measuring the complex design by conventional method which is using the distometer, TLS is the new method that can be implemented to provide the accurate dimension of complex design for each parcel. The conventional system provide information in single point only compare to TLS which able to record huge numbers of point. Moreover, TLS gives more advantages in understanding the scanned data especially when dealing with complex building.

The TLS is not using any physical method while collecting the data. According to Fröhlich et al., 2004, TLS is using remote sensing technique because individual to hold the sign of the target in process of collecting data is not required. Most of the different industrial sector such as engineering and architecture today require the 3D model of building especially for multi-storey building (Abdul-Rahman et al., 2005). In addition, they also needs precise data in order to be able to have an as-built analyzation especially for indoor mapping. Thus, it is important to obtain accurate data for preparation of strata plan and by using the laser scanner can fulfil their requirements. The laser scanner can gives the data with full of accuracy and increase the speed of Three Dimensional (3D) data acquisition of digital as-built generation process (Aziz et al., 2016).
The application field that involved with the laser scanner are topography, industrial, engineering and also in forensic field. The market of laser scanners for terrestrial applications has developed quite successfully and the laser scanners are seen as one of the surveying instruments that meet the requirements of industrial applications (Fröhlich et al., 2004). At first, the invention of the laser scanning is just suitable for short-range only. However, the uses of this laser scanning is keep increasing, and have pushed the development of the technology to invent the new updated laser scanner. Thus, the mid-range and long-range laser scanner has been introduced.

\subsection{As-built Survey}

Conventional method for as-built survey for measuring the distance of each parcel in the building is by using Distometer. It has been used widely to measure the distance because of its size which is small and handy. But it also has the weaknesses. The reading from Distometer cannot be recorded like TLS, and all the measurement needs to be written on the paper or on the map. It also unable to provide the three- dimensional (3D) model of the building. The handling of this instrument is same as the application of total station or Theodolite and GPS. User needs to find the suitable station to set up this instrument, and wait to collect the data.

For this study, the Terrestrial Laser Scanning which is Leica C10 (Figure 1) was tested to know the capability of TLS in building survey. The GeoSlam Zeb-Revo handheld mobile laser scanning (Figure 2) were also compared with the data collected by Leica $\mathrm{C} 10$, together with data collected by Agatec distometer as conventional method. The aim of this research is to study the 
limitation uses of Terrestrial Laser Scanning and its suitability for building survey.

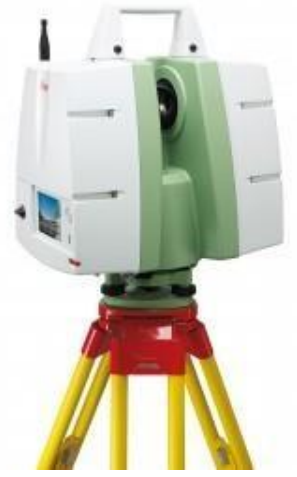

Figure 1: Leica C10.

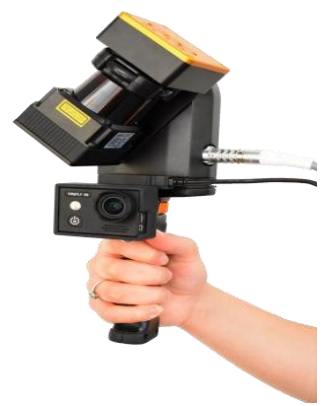

Figure 2: GeoSlam Zeb-Revo.

\subsection{Highlighted of Study}

The demand of building survey work has made the surveyor needs to obtain the data with full accuracy and time saves. Besides that, undertaking measured surveys and providing plans, elevations and sections of existing buildings and sites remains at the heart of the Building Surveyors. Most surveyors still used the conventional method when taking measurements on site which is by using measuring tape. In addition, Distometer was used to measure the dimensions of each parcel and the building but it still considered not relevant because these has to rely on accuracy, completeness and neatness of the sketches and notes made on the field. The recording of information on site is traditional undertaken on paper and surveyor plot the plan in the office by using Computer Aided Design (CAD) Software. It may lead to a few problems such as missing the paper that contain the information and misunderstanding the sketches that has been drawn at the site. It is visualized that by using the laser scanner for taking the internal measurement can provide the accurate plan in far less time than using present methods.

This research was carried out to improve the conventional method in collecting the detail for the purpose in building survey work by using the terrestrial laser scanner. By using the different type of laser scanner which is Terrestrial Laser Scanning (TLS) and Mobile Laser Scanning (MLS), the accuracy elevation of both systems were carried out. Both of laser scanners can detect thousands of point clouds data in a second. Thus, this building survey will analyze the accuracy of data obtained from both laser scanner and it will be compared with the building plan. The recommended method for most efficiency way in undertaking building survey will be determined. Hence, the time taken for acquiring the data will be compared for both laser scanner which is Terrestrial Laser Scanner and Mobile Laser Scanner. Then justification about the issues and limitation of Terrestrial Laser Scanner in building survey were carried out in this research.

Users of building plan usually will translate what they see on a flat paper from $2 \mathrm{D}$ to $3 \mathrm{D}$, and it is inconvenience for them because it required a high imagination and skill in understanding the plan (Dredge and Coiacetto, 2011). Thus, to make the work efficiency, the 3D model of the building must be developed. Even though TLS able to record thousands of point clouds at one time, but in order to get the 3D model, it still needs to be processed. Point cloud contains very rich of geometric details and a large number of polygonal elements, so it can cause the problems to generate the 3D model (Manferdini et al., 2010). 3D scanned point clouds for both laser scanners were develop unstructured sets of data so its need skill and knowledge to produce a good result. The point cloud processing usually takes a longer time compare to its data capturing. Therefore, surveyor needs to do a lot of study to improve the way in obtaining the data and the efficiency of TLS in building survey will be compared with the MLS. Different type of software will require different skill and knowledge to generate the 3D model and different format data will be produce. The comparison of the 3D model format was carried out to study the ability of the result for other user from different field.

\subsection{Significance of Study}

These days, as the building development has quite increasing in development sector, the demand of the accurate building plan is increasing. Requirement for obtaining data with full of accuracy is necessary to produce building as-built plan. The importance of Building Survey is to make sure that every parcel has its own title and all the maintenance work and new development for that building are under control. Thus, this research is carried out to implement and study whether the Terrestrial Laser Scanning is capable to obtain data for building survey with full accuracy and time saves. The technique in obtaining the data makes us understand the principle of terrestrial laser scanner and the limitation usage of TLS for building mapping work.

Study about terrestrial laser scanner for data acquisition, registration and point cloud processing, modelling, generalization and visualization were conducted in this research. The dimensional of measurement from different type of laser scanner with conventional method will be made including the general comparison such as time consuming. Other than evaluate the ability of Leica Cyclone software to process the point cloud data in term of accuracy, relevance and the implications to the user, this research also will evaluated the ability of Autodesk Revit to form the 3D model for indoor building. The analysis from the measurement by Terrestrial Laser Scanning and Mobile Laser Scanning were compared. The visualization of 3D model of the building from different types of measurement instrument was made.

The 3D work especially for building development in gaining the accurate data got higher demand in the important profession like engineering, architectural and most important in surveying field. The application for 3D laser scanning in these types of industries also seems to be virtually limitless and the benefits of the technology need to be continually applied to new and different industries so that more people can understand the usefulness of 3D Laser scanning. Therefore, this study can give the comprehensive discussion on improving the new method of gathering building data in term of accuracy for two different types of measurement instrument and the limitation of the terrestrial laser scanner in building survey. 


\section{METHODOLOGY}

\subsection{Methodology Flowchart}

Figure 3 shows the flowchart that has been referred to conduct this study. There were four (4) phases in this study which comprises of preliminary study, data acquisition, data processing, result and analysis. These four phases set out the way this study needs to be conducted and is designed to assist in the implementation of the study. In phase one (1), the literature review and the understanding about TLS need to be done. The problem statements were determined followed by the aim and scopes of study to ensure this study done as planned. The study area of this study as shown in Figure 3. This study covered the whole 3D GIS Research Laboratory located at level 2, Block C05, Faculty Geoinformation and Real Estate, UTM, Johor.

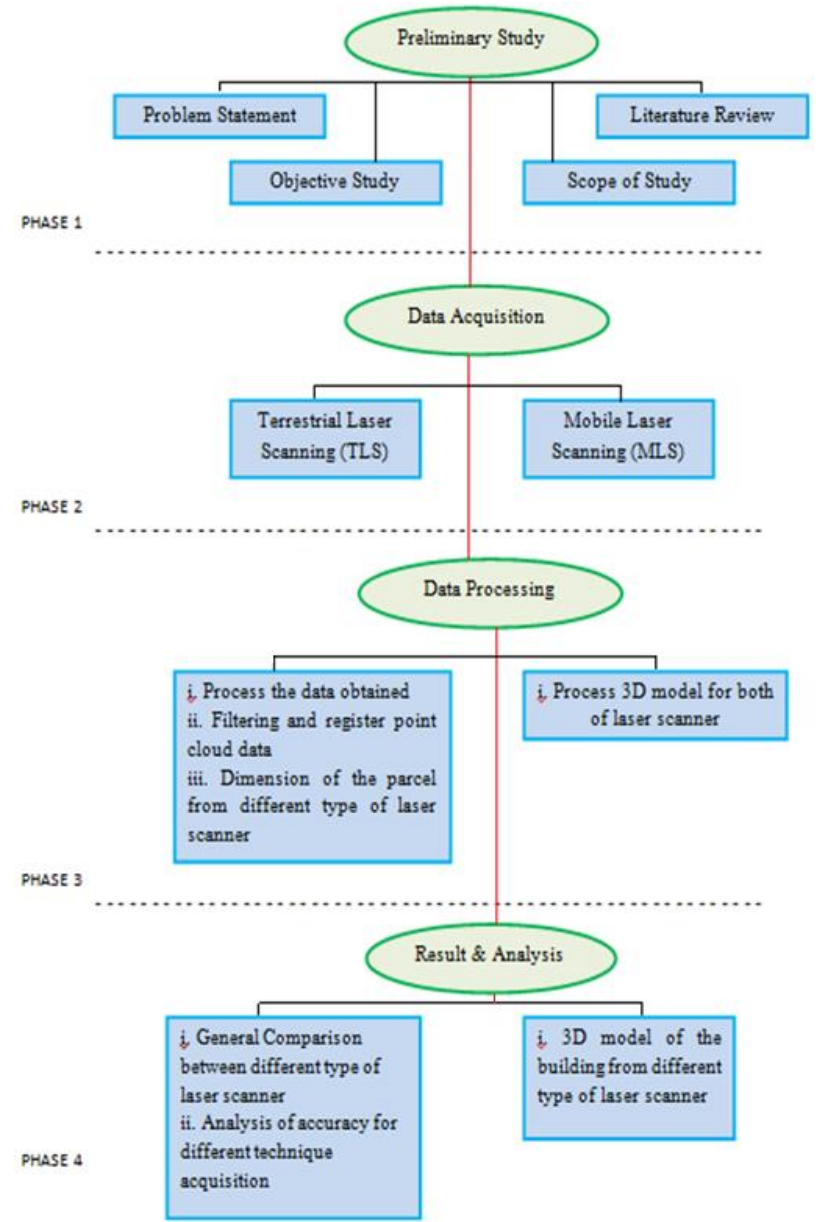

Figure 3: Methodology flowchart.

In phase two (2), all the raw data from different technique were collected. The data included point cloud data from Leica $\mathrm{C} 10$ and GeoSlam Zeb-Revo handheld. All the collected point cloud data then were compared with the data dimensions collected by Agatec distometer as the conventional method.

\subsection{Data Acquisition}

A plan of survey area was sketch on paper to determine the location of scanner and the target (Figure 4). It is to ensure that all the information and detail of the building was covered. This research used only one scanner to scan the whole survey area so it needs to move to another scan station to scan the next part of the area. 6 units of sphere targets and 7 black and white targets with diameter $\pm 15 \mathrm{~cm}$ respectively were used. The placement of targets should be considered with the position of scanner because it acts as a control point for point cloud registration. At least three targets should be clearly seen by each other and can be scanned by scanner for each station.

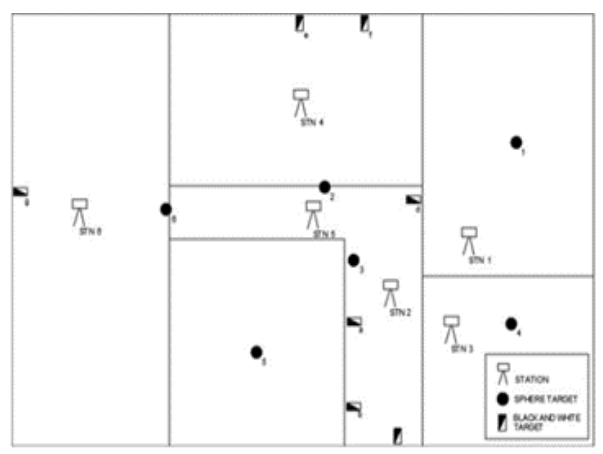

Figure 4: Position of the targets and laser scanner during data collection process.

\subsubsection{Data Acquisition using Leica C10}

The scanning procedures can be proceeds after the file project was created. Set up the scanning parameters. Medium resolution is chosen due to its capability in scanning average data. This resolution needs 10 to 18 minutes to scan one area together with the image. It is scanned by grid with point spacing $1 \mathrm{~m} \times 1 \mathrm{~m}$ (horizontal spacing $\mathrm{x}$ vertical spacing) and scan range is $100 \mathrm{~m}$. The data given is point cloud, and an image with colored point cloud. Medium resolution is chosen for scanning the whole one area, while highest resolution was chosen to scan every target that can be seen and scanned from the scan station. Different types of resolution selected because it can differentiate the whole scanned area with the targets during registration and processing. To scan only the selected target, the "field of view" needs to be determined and "quick scan" must be selected on the Scan Parameter page. After the scanning process completed, the scanned data can be seen automatically at the MMI screen on the Leica C10 (Figure 5). Only then, the scanner can be moved to the next station. The standard set up must be done before moves the Leica $\mathrm{C} 10$ scanner. It is a must to ensure the new station folder has been created up to avoid the overlay data. All the raw data then were downloaded to the computer for data processing.

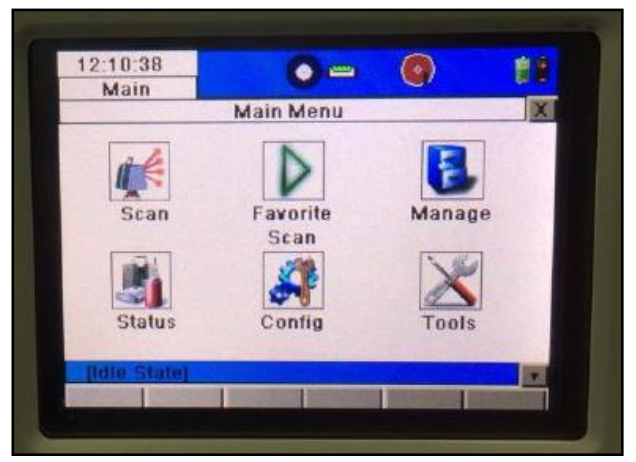

Figure 5: MMI screen display.

\subsubsection{Data Acquisition using GeoSlam Zeb-Revo}

This technique is easier compared to the Leica C10 method. When the rover was in scanning mode, press the start button at the side of Zeb-Revo head scanner and start button on Go-Pro Camera. The Zeb-Revo rover scanned the whole area by rotating the head scanner in 270 degree and range up to $15 \mathrm{~m}$. After 
completing scanning process for the whole study area, the ZebRevo rover needs to be put back on the same platform for initialization. Press stop button and let the rover in stationary mode for approximately 5 to 10 seconds. The LED flash is switched to orange color for de-initialized.

Once the rover finishes the de-initialization, all the scanned data can be transferred right away from the scanner to the computer as shown in Figure 8. All the data were in las.* and laz.* format and image was in Jpeg.* format. The software used for transferring from Zeb- Revo rover to the computer is Geo Slam software.

\subsubsection{Data Acquisition using Agatec Distometer}

As for conventional method, the Agatec Distometer was used. This study used Agatec Distometer as for the conventional method. The study area was same as the Leica C10 and ZebRevo rover which is 3D GIS Research Laboratory. All the dimensions must be measured and obtained. Every parcel and every corner was measured to obtain the distance from the edges of the building to other corner.

For this technique, measurement process was more detail. Any parcel and angle of the study area needs to be measured. The measurements were taken three times and the average was calculated. It was recorded manually on the paper. When all the parcels have been completely measured, the dimensions will be proceeds to next step which is processing data.

\subsection{Data Processing}

In phase three (3), all the raw point cloud data were transferred to the specifics software. Different software has been used due to different technique of data acquisition. For TLS Leica C10, Leica Cyclone Software was used for registration data process. While for Zeb-Revo handheld mobile laser scanner doesn't required to register the point cloud.

All the point clouds data acquired from TLS need to undergo registration process. It is to match data of two scans with different position tied up together and be in one image. This research has 6 different position of the scanner, so registration process is a must to combine all the point cloud data to be in one image of the study area (Figure 6).

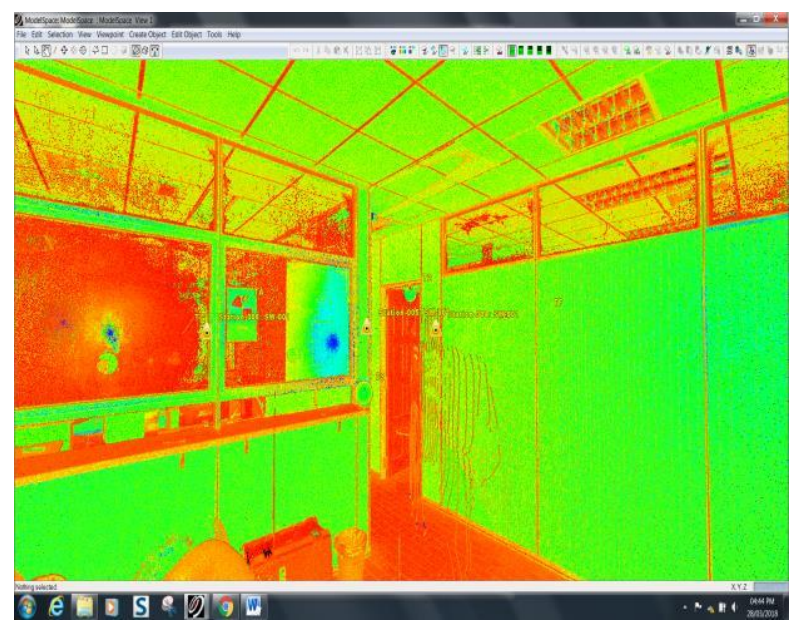

Figure 6: TLS data registration

But, before the registration processed begun, all the scanned data should be checked through the constraint list after step auto-add constraint and register. If the error in constraint list is over than $0.010 \mathrm{~m}$ or $10 \mathrm{~cm}$, the registration data cannot be accepted. Limit of error in cloud constraint is described in Table 1.

Table 1: Error value in cloud constraint
\begin{tabular}{|c|l|}
\hline $\begin{array}{c}\text { Limit of error } \\
\text { value (meter) }\end{array}$ & \multicolumn{1}{|c|}{ Description } \\
\hline $\int 0.030$ and above & $\begin{array}{l}\text { Tolerable. It may require re-picking or } \\
\text { subsample percentage increase }\end{array}$ \\
\hline $\int 0.020$ to 0.030 & $\begin{array}{l}\text { Acceptable. The measurable error, } \\
\text { within most design requirements. }\end{array}$ \\
\hline $\int 0.000$ to 0.020 & $\begin{array}{l}\text { Excellent. It below than measurable } \\
\text { limits. }\end{array}$ \\
\hline
\end{tabular}

The unwanted point cloud data that can disturb the measuring process needs to be removed. It is because the measuring process is an important process to get the dimensions of the parcel for each different technique. Hence, cleaning and filtering process for TLS Leica C10 and Zeb-Revo handheld MLS data was done by using Autodesk Recap. Thus, the indoor building can be viewed clearly as shown in Figure 7 and Figure 8.

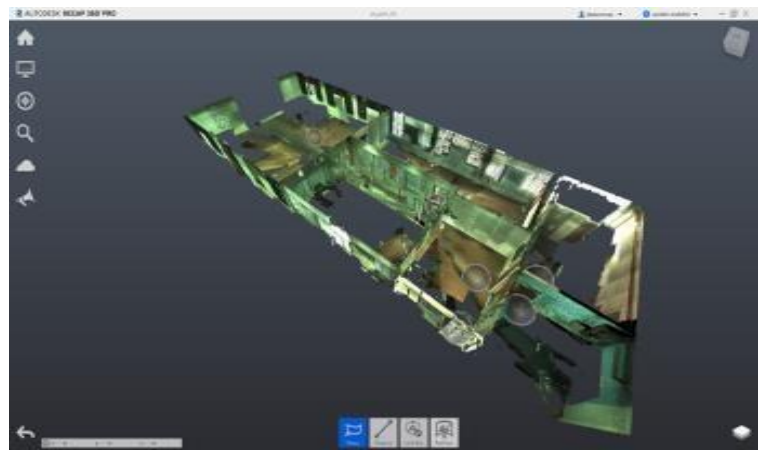

Figure 7: The parcel acquired from TLS viewed in Autodesk Recap.

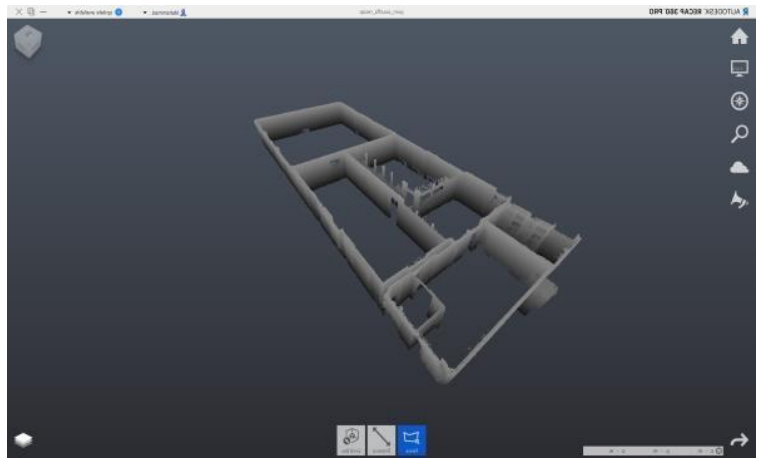

Figure 8: The parcel acquired from MLS viewed in Autodesk Recap.

Then, the measurement process can be proceeds. Data from TLS and MLS were processed by using Autodesk Revit Software. Raw cleaned data from both scanners were import directly from Autodesk Recap to Autodesk Revit by Point Cloud Tool in *.rcp format. Measuring process start by clicking at the point cloud which appear in the interface at the Revit Software. For TLS data it is easier to do the dimension measurement process because the point cloud data comes with an image. The image is a colored point cloud data that can give real visual at the scanned area. Meanwhile, the scanned data from MLS does not provide the image. 
The linear dimension tool was used for dimensioning the parcel. Select the length which needs to be measured, and the dimension will be given automatically. Skill and knowledge in selecting the point cloud is very important since it involves the dimension of the length itself.

The process to produce the 3D model of the study area also was done by using Autodesk Revit. The cleaned point cloud data was imported into the Revit through Point Cloud tool. The wall needs to be created. In order to add the wall, the architectural wall has been selected because this type of wall is suitable for interior and exterior wall. The height of the wall is 10 feet which \pm 3 meter. Make sure the chain box was ticked to connect each wall. Place the wall based on the true dimensions that has been measured during the measurement processing before this. Continue this step to place the wall until complete all the parcel.

Next step in generating the 3D model is to create the section box as shown in Figure 9 which has control button that can be used to crop off the model to give user clearly view at the inside of the model especially for the complicated model. It also useful when processing involved only in specific room or specific wall. Thus, it can ensure that the model can be generated with accurately.

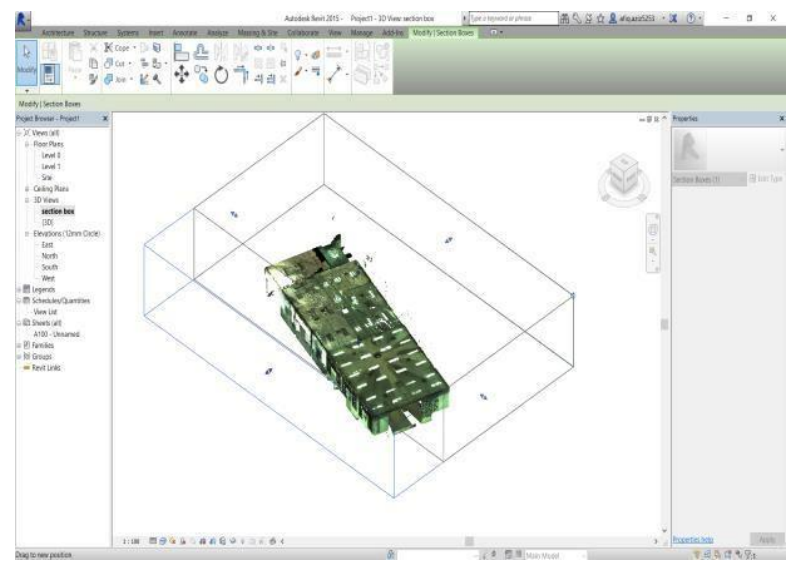

Figure 9: The section box to generate 3D model.

The dimensions from three different techniques were analyzed. Both data from TLS and MLS were compared with Distometer data to analyze the capability of laser scanner systems for building dimensional \& measurement. The visualization of 3D model from both laser scans were analyzed.

\section{RESULTS AND DISCUSSION}

The 3D modeling analysis and 3D visualization analysis was made to study the suitability of TLS for strata building. The 3D modeling analysis consisted of measurement analysis between Terrestrial Laser Scanning, handheld Mobile Laser Scanning and Distometer. The results were compared for accuracy evaluation. Meanwhile, the 3D visualization analysis is a comparison of the presentation of model that was produced from TLS and MLS collected scanned data.

\subsection{Accuracy Analysis}

A total of 8 dimensions of a parcel were compared by using three different techniques which are by TLS, MLS and Distometer. The analysis was made to compare the accuracy of measurement and determine the suitability of the TLS for building survey and the best technique that should be used in building survey work. The comparison was made based on the same parcel, and the same point. Figure 10 shows the point of distance measurement that been referred. Meanwhile, Table 2 shows the point of distance measurement result for three different techniques of TLS, MLS and Distometer.

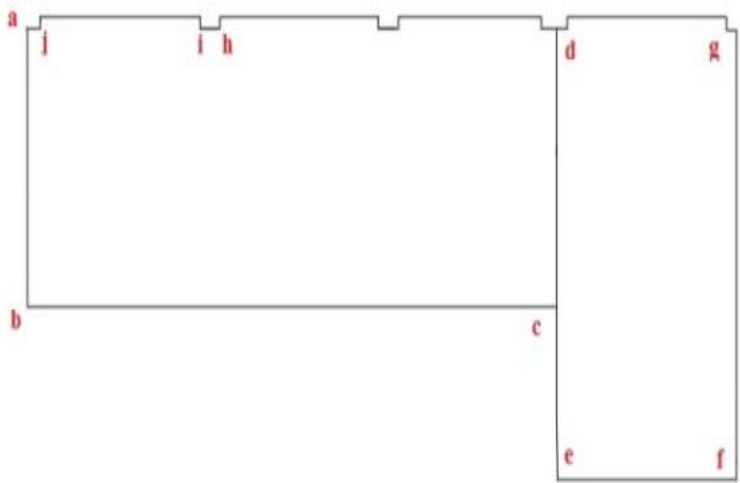

Figure 10: Points of measurement.

Table 2: Result of distance measurement.

\begin{tabular}{|c|c|c|c|}
\hline POINT & $\begin{array}{c}\text { TLS } \\
(\mathrm{m})\end{array}$ & $\begin{array}{c}\text { ML } \\
\mathrm{S}\end{array}$ & $\begin{array}{c}\text { Distometer } \\
(\mathrm{m})\end{array}$ \\
\hline $\mathrm{a}-\mathrm{b}$ & 4.150 & 4.200 & 4.180 \\
$\mathrm{~b}-\mathrm{c}$ & 11.000 & 10.850 & 11.073 \\
$\mathrm{~d}-\mathrm{e}$ & 6.500 & 6.500 & 6.475 \\
$\mathrm{e}-\mathrm{f}$ & 3.500 & 3.510 & 3.541 \\
$\mathrm{f}-\mathrm{g}$ & 6.500 & 6.490 & 6.505 \\
$\mathrm{~g}-\mathrm{d}$ & 3.500 & 3.510 & 3.520 \\
$\mathrm{~h}-\mathrm{i}$ & 0.350 & 0.340 & 0.348 \\
$\mathrm{i}-\mathrm{j}$ & 3.300 & 3.250 & 3.319 \\
\hline
\end{tabular}

Based on the result above, the graph comparison was made (Figure 11). From the graph below, it shows only slightly different between the distance measurements. The maximum distance difference between Distometer is $0.223 \mathrm{~m}$ in point $\mathrm{b}-\mathrm{c}$ by using MLS, while the minimum distance difference is $0.002 \mathrm{~m}$ in point $\mathrm{h}-\mathrm{i}$ by using TLS.

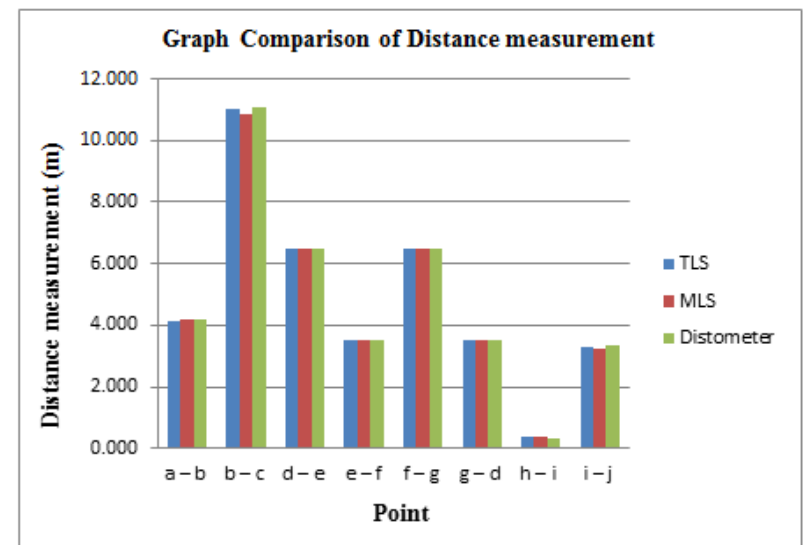

Figure 11: Graph comparison of distance measurement.

The maximum difference of dimension from MLS and Distometer is because of human error during measurement process between two points or error during cleaning and filtering phase. While the minimum difference of dimension from TLS and Distometer is because of the TLS ability to give more accurate position up to millimeter level at a certain point.

Table 3 shows the comparison measurement between Distometer, TLS and MLS. Meanwhile, Figure 12 show graph 
comparison of error between Distometer, TLS and MLS respectively.

Table 3: Comparison measurement between Distometer, TLS and MLS.
\begin{tabular}{|c|c|c|c|c|}
\hline POINT & $\begin{array}{c}\Delta \text { Disto }- \\
\text { TLS } \\
(\mathrm{X})(\mathrm{m})\end{array}$ & $\begin{array}{c}\mathrm{X}_{2} \\
(\mathrm{~m})\end{array}$ & $\begin{array}{c}\Delta \text { Disto }- \\
\text { MLS } \\
(\mathrm{X})(\mathrm{m})\end{array}$ & $\begin{array}{c}\mathrm{X}_{2} \\
(\mathrm{~m})\end{array}$ \\
\hline $\mathrm{a}-\mathrm{b}$ & 0.030 & 0.001 & -0.020 & 0.000 \\
$\mathrm{~b}-\mathrm{c}$ & 0.073 & 0.005 & 0.223 & 0.050 \\
$\mathrm{~d}-\mathrm{e}$ & -0.025 & 0.001 & -0.025 & 0.001 \\
$\mathrm{e}-\mathrm{f}$ & 0.041 & 0.002 & 0.031 & 0.001 \\
$\mathrm{f}-\mathrm{g}$ & 0.005 & 0.000 & 0.015 & 0.000 \\
$\mathrm{~g}-\mathrm{d}$ & 0.020 & 0.000 & 0.005 & 0.000 \\
$\mathrm{~h}-\mathrm{i}$ & -0.002 & 0.000 & 0.008 & 0.000 \\
$\mathrm{i}-\mathrm{j}$ & 0.019 & 0.000 & 0.069 & 0.005 \\
SUM & $\sum$ & 0.009 & $\sum$ & 0.057 \\
RMSE & $\sum \mathbf{8}$ & $\mathbf{0 . 0 0 1}$ & $\sum \mathbf{8}$ & $\mathbf{0 . 0 0 7}$ \\
\hline
\end{tabular}

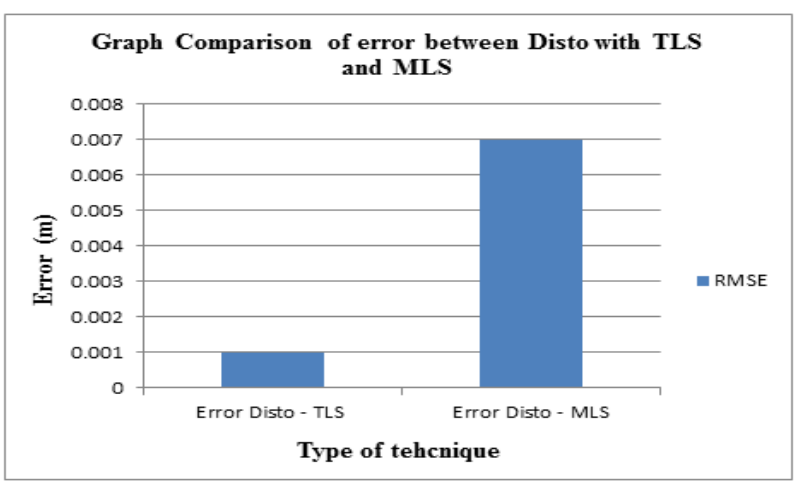

Figure 12: Graph comparison of error between Distometer with TLS and MLS.

The RMSE value was used on the Table 3 to compare the error between Distometer with TLS and Distometer with MLS. The RMSE value of Distometer with TLS is smaller than RMSE value of Distometer with MLS, which is $0.001 \mathrm{~m}$ compared to $0.007 \mathrm{~m}$. The smaller the RMSE value with distometer value is better. The graph shows huge difference between both RMSE with $0.006 \mathrm{~m}$. It is proved that TLS technique is better than using MLS technique in acquiring data for strata building. TLS can give good better accuracy with small RMSE value rather than MLS.

\subsection{Visualization Analysis}

The analysis of 3D visualization was done by comparing the model of indoor study area which were produced by the same software, Autodesk Revit Software but different in technique acquisition which is by Terrestrial Laser Scanning Leica C10 and GeoSlam Zeb-Revo Handheld Mobile Laser Scanning. The main focus for this analysis is to know the capability of different laser scanning in obtaining point cloud data to generate the $3 \mathrm{D}$ model. The 3D model for data from TLS Leica C10 is much easier to process compared with the data from Geo Slam Zeb-Revo handheld MLS. It is because the scanned data from the TLS Leica C10, comes with the image, whereas the scanned data from MLS did not provide the image. The image can be used as a reference to the user in generating the 3D model processing. Figure 13 and Figure 14 show the 3D model from MLS and TLS.

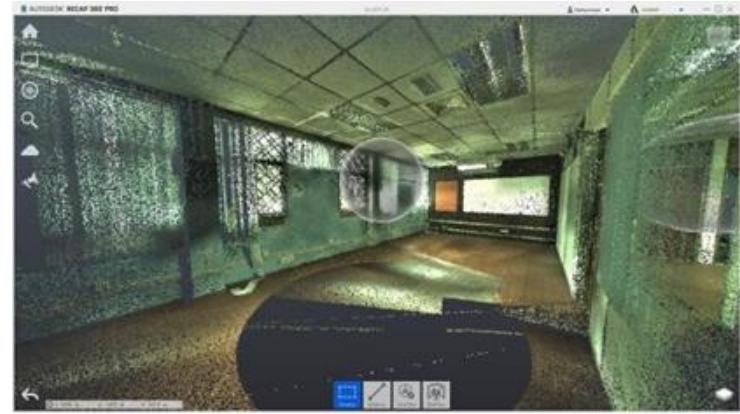

Figure 13: 3D model from TLS comes with an image.

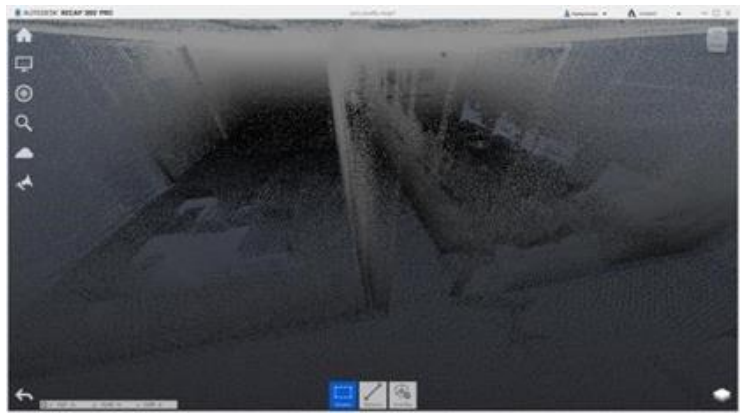

Figure 14: 3D model from MLS without an image.

The 3D models that were generated from both of laser scanners did not have too much difference. The difference in dimension gave impact to the model of the building. So, it is important to scan the whole of survey area to achieve a good model. The skill and knowledge in processing also can affect the data.

\subsection{General Comparison: TLS vs. MLS vs. Distometer}

Based on the Table 4, there are some general comparison between these three methods, TLS, MLS and Distometer. The time taken for Distometer was 70 minutes (1 hour 10 minutes) to complete for whole area. While for TLS, it required 60 minutes ( 1 hour) which is quite longer than MLS which only took 30 minutes to scan the whole area. Distometer took longer time because it needs measure from one edge to another edge. Other than that, it also has to record the data on the paper and needs to sketch and has to get the idea of measure the shape of the building.

Table 4: General comparison between TLS, MLS and Distometer.

\begin{tabular}{|c|c|c|c|}
\hline Item & TLS & MLS & Distometer \\
\hline $\begin{array}{l}\text { Time taken for } \\
\text { data collection }\end{array}$ & $\begin{array}{l}60 \text { minutes (1 } \\
\text { hour) }\end{array}$ & 30 minutes & $\begin{array}{c}70 \text { minutes } \\
(1 \text { hour } 10 \\
\text { minutes })\end{array}$ \\
\hline Manpower & 3 persons & 1 person & 2 persons \\
\hline $\begin{array}{l}\text { Scan point per } \\
\text { second }\end{array}$ & 50000 points & 43200 points & $\begin{array}{l}\text { One point per } \\
\text { scan }\end{array}$ \\
\hline $\begin{array}{l}\text { Concept of } \\
\text { capturing data }\end{array}$ & Static & Mobile & None \\
\hline $\begin{array}{l}\text { No. of scan } \\
\text { station }\end{array}$ & 6 stations & None & None \\
\hline $\begin{array}{l}\text { Registration } \\
\text { process }\end{array}$ & Compulsory & None & None \\
\hline $\begin{array}{l}\text { Time taken for } \\
\text { data processing }\end{array}$ & $\begin{array}{l}120 \text { hours } \\
\text { (5 days) }\end{array}$ & $\begin{array}{l}72 \text { hours } \\
\text { (3 days) }\end{array}$ & $\begin{array}{l}48 \text { hours } \\
\text { ( } 2 \text { days) }\end{array}$ \\
\hline $\begin{array}{l}\text { Cost of } \\
\text { instrument }\end{array}$ & RM $100 \mathrm{~K}$ & RM $120 \mathrm{~K}$ & RM $2.5 \mathrm{~K}$ \\
\hline
\end{tabular}


Since the TLS also needs to scan at least three targets to combine the data of different station, hence it also took longer time compared to the MLS. Based on Table 4, the time taken for data processing from both of laser scanner system took longer time compared to Distometer. It is because Distometer views the data in $2 \mathrm{D}$, while point cloud data from laser scanner system can be processed and viewed in 3D model.

However, the processing needs high skill and knowledge. For the beginner it would be difficult to do the modelling and dimension measurement. Unlike the expert it will take lesser time to do the processing. For this research, it takes 5 days to process the data. Therefore, the user needs a good training not just handling the equipment but to process the data. There are a lot of software that can process this point cloud data, however the surveyor needs to study whether that software is good enough for them according to their objective of work and its accuracy.

\subsection{Suitability of TLS for Building Survey \& Mapping}

For building survey work, the accuracy of dimensions of every parcel is important. It is because the area of parcel can affect the price of the maintenance fee, the selling price and etcetera. So, the implementation of TLS for building survey should has more consideration and discussion.

The TLS system is still considered as an early phase of development compared with the existing technique in obtaining strata data, which is by using Distometer, all the dimension data needs to write on the paper. The dimension could be wrong due to carelessness of the surveyor during data collection, and the needs to make sure that paper must always be in its placed for the next processing to avoid missing data. While TLS system automatically will record and save the scanned data. So, it made the data more trusted, and can avoid missing data.

TLS measurement cannot penetrate the wall. The wall thickness is important to determine the boundary of the parcel and that is the reason the Distometer still becomes a good choice in building survey because Distometer can get all the dimension of the parcel including the thickness of the wall other than easy to handle since it is in small size. While for TLS systems, it required an additional handheld laser scanner to measure the thickness of the wall. And of course, it also required an additional cost and time to combine and process the data.

With the recorded data, client can use the data for further work. And with the high accuracy dimensions of the parcel, the developer can create the Building Information Management (BIM) to ease their management of the building. They can use the information of every parcel to establish the database of the building to maintain the safety of the parcel owner and maintaining the facilities of the building. But due to the high price of TLS, most of the surveyor and the developer will choose the Distometer because it is more affordable compared to the TLS system.

There are some limitations of laser scanner and may be influenced by several factors, which are: (1) The existence of water and glass window, because the laser cannot penetrate through the water due to different density; (2) The laser can be refracted when contacted with the glass window; (3) During the processing, skill and knowledge will be very important to ensure the dimension is accurate.

But from the measurement analysis, the measurement difference between all three techniques has only slight differences. The dimension from both laser scanners still can be used for making measurement for building survey since the building plan calculation using one decimal point. For example, dimension showed in building plan is $4.2 \mathrm{~m}$, and dimension at point a-b from MLS is $4.2 \mathrm{~m}$, from TLS $4.150 \mathrm{~m}$ and Distometer $4.18 \mathrm{~m}$. When the values are rounded up to the nearest decimal point will be $4.20 \mathrm{~m}$ same as in the building Plan.

\section{CONCLUSIONS}

TLS technology has been tested whether it can be used to replace conventional method such in term of accuracy, time taken for data collection and data processing, the accessibility and flexibility at particular area. The result shows that there was only slightly different of the RMSE between the Distometer - TLS, and Distometer - MLS. The laser scanner system can be used to obtain the data for indoor and outdoor of building. The new invention in building survey is a good thing in order to replace the conventional method with the new idea. It is because technological requirement always needed not just in the construction field, but also in most of the field.

This study was carried out to study the limitation and suitability of the TLS for building survey. The 3D modeling analysis and $3 \mathrm{D}$ visualization analysis was produced. The $3 \mathrm{D}$ modeling analysis consists of the accuracy evaluation for TLS, MLS and Distometer technique. The maximum distance difference between Distometer is $0.223 \mathrm{~m}$ which is in point $\mathrm{b}$-c by using MLS and the minimum distance difference is $0.002 \mathrm{~m}$ in point $\mathrm{h}-\mathrm{I}$ by using TLS. The RMSE for TLS technique is $0.001 \mathrm{~m}$ while the RMSE for MLS technique is $0.007 \mathrm{~m}$. The difference value of these two techniques is $0.006 \mathrm{~m}$. It shows the accuracy between three techniques not much different in the form of decimal point.

Meanwhile, the 3D visualization analysis that compare the presentation of the model was produced which shows the data from TLS is easier to process and generate the 3D model because it comes with an image and it can be as a reference and helps user in generating the 3D model of the building processing compared with MLS data.

\section{ACKNOWLEDGEMENTS}

The authors would like to express their sincere appreciation to Universiti Teknologi Malaysia (UTM) under GUP Tier 2 (Vot. 14J96, Vot. 03K19, Vot. 15J12) for supporting this study.

\section{REFERENCES}

Arayici, Y., 2007. An approach for real world data modelling with the 3D terrestrial laser scanner for built environment. Automation in construction, 16(6), 816-829.

Fröhlich, C. and Mettenleiter, M., 2004. Terrestrial laser scanning new perspectives in $3 \mathrm{D}$ surveying. International Archives of Photogrammetry, Remote Sensing and Spatial Information Sciences, 36(Part 8), W2.

Abdul-Rahman, A. Stoter, J., and Nordin, A., 2005. Towards 3D cadastre in Malaysia. Paper presented at the Proceedings of the Joints International Symposium \& Exhibition on Geoinformation 2005 \& International Symposium on GPS/GNSS 2005 (ISGGNSS 2005). 
Aziz, M. A., Idris, K. M., Majid, Z., Ariff, M. F. M., Yusoff, A. R., Luh, L. C., and Chong, A. K., 2016. A study about terrestrial laser scanning for reconstruction of precast concrete to support QCLASSIC assessment. International Archives of the Photogrammetry, Remote Sensing and Spatial Information Sciences, 42, 135-140.

Giussani, A., and Scaioni, M., 2004. Application of TLS to support landslides study: survey planning, operational issues and data processing. International Archives of Photogrammetry, Remote Sensing and Spatial Information Sciences, 36(8/W2), 318-323.

Manferdini, A. M., and Remondino, F., 2010. Reality-based 3D modeling, segmentation and web-based visualization. Paper presented at the EuroMediterranean Conference.

Sepasgozar, S., Lim, S., Shirowzhan, S., and Kim, Y., 2014. Implementation of as-built information modelling using mobile and terrestrial lidar systems. Paper presented at the ISARC. Proceedings of the International Symposium on Automation and Robotics in Construction. 